\title{
Midwifery continuity of care: Potentiality of midwives adherence to the new model of care
}

\author{
Yahaya Jafaru \\ Department of Nursing Science, College of Health Sciences, Federal University Birnin-Kebbi, \\ Kebbi State, Nigeria. *Email: jafaruyahaya2015@yahoo.com
}

\begin{abstract}
Background: The midwifery continuity of care is gaining more attention, and the WHO recommends the use of its models to provide antenatal, intrapartum and postnatal care in a setting where effective midwifery programme exists. However, in many countries, implementation of continuity of care model has been challenging for midwives.

Purpose: The purpose of the study was to assess the potentiality of midwives adherence to midwifery continuity of care as a new model of care.

Method: The research is descriptive that adopted cross-sectional design. The population of the study was the midwives serving in antenatal clinic (ANC), maternity and labour units. The instrument for data collection was researcher made, self-administered questionnaire. Census sampling was used in taking the entire midwives of the units as the subjects of the study. The results of the study were presented in frequencies and percentages, with Chi-square as a statistical tool for inferential analysis.

Results: Generally, $46.3 \%$ of the respondents were having good potentiality, $44.8 \%$ were having poor potentiality, and only $9.0 \%$ were having very good potentiality. $56.7 \%$ of the respondents with $0-5$ years of experience were having poor potentiality, in contrast with $27.3 \%$ in respondents with $>15$ years of experience. $34.6 \%$ and $53.7 \%$ of the respondents that were midwives and those that were nurse-midwives in specialty respectively were having good potentiality to MCC adherence. There is no significant association between respondents' years of experience and their potentiality to MCC adherence, $P>0.05$. There is no significant association between respondents' specialty and their potentiality to MCC adherence, $P>0.05$.

Conclusion: The respondents of this study had a moderate potentiality to MCC adherence. The possibility of midwives adherence to MCC can be improved if it is introduced into the system with some modifications and flexibilities; and when the midwives realise its positive impact on maternal and new-born health.
\end{abstract}

\section{Keywords: Adherence; Continuity of care; Midwives; Model of care; Potentiality}

\section{INTRODUCTION}

Philosophically, midwifery practice is about strengthening family relationships, empowerment and normal birth (Killingley, 2016). This is done more effectively through patient centered care, and continuity of care agrees with the call for making care to be patient centered (Burau \& Overgaard, 2015). In midwifery, it has been proven that continuity of care is safe and developed trust between midwife and woman which bring about empowerment and informed choice (Boyle et al., 2016). Based on the human right approach, the concern about women is not only on avoiding death and morbidity, but also promoting health and wellbeing with respect, dignity and rights (World Health Organization [WHO], 2016a), an issue of great concern to developing countries. Thus, midwifery continuity of care (MCC) models are highly recommended for maternal and neonatal health (National Maternity Review, 2016; WHO, 2016b).

The World Health Organisation (2014) asserted that about $99 \%$ of maternal deaths occur in lowresource settings and most of it can be prevented; and approximately 2.6 million babies from lowresource settings were stillborn in 2015 (Blencowe et al., 2016). It is estimated that in the occurrence of each maternal death there is between $50-100$

\footnotetext{
Yahaya Jafaru

Department of Nursing Science, College of Health Sciences, Federal University Birnin-Kebbi, Kebbi State, Nigeria. Email: jafaruyahaya2015@yahoo.com
} 
severe maternal morbidity suffered by other women (Geller, et al., 2018; Miller, et al., 2016). However, a review by Sandall et al. (2015) revealed that continuity of care improve the health outcomes of women and their babies.

Midwifery is a health care profession that offers care to childbearing woman during the periods of pregnancy, labour and post-partum. It provides care to newborn, primary care to healthy pregnant women, family planning and menopausal care (Oyetunde, 2014). In Nigeria the midwifery service is largely through a traditional midwifery practice by which midwives run a shift duty in rotation (Morning, evening and night duties) with some days given as off duty between every shift. Thus, a pregnant woman would be having contact with many different midwives through her pregnancy, delivery and post-partum care. Also, traditional birth attendants (TBAs) provide midwifery services, most commonly in rural areas (Oyetunde, 2014). However, in 2009 the Nigerian government introduces a Midwifery Service Scheme (MSS) in which the newly qualified, unemployed, and retired midwives are recruited and deployed to public primary health facilities especially in rural areas (Okeke et al., 2017).

MCC are models of maternity care by a single midwife familiar to the woman, the primary midwife, back up by a partner midwives. The primary midwife sees the woman consistently during pregnancy, labour and post-natal period and is supported by teams of specialists through referral (Sandall et al., 2016). The two main continuity of care models are case load model, in which one midwife cares and facilitate relational care for up to 45 women; and team midwifery model in which group of four to six midwives provide care for up to 360 women throughout the period of pregnancy, labour and post-natal period (WHO, 2016b). These types of continuity of care are called "relational continuity" or "personal continuity". They enhance trust and familiarity between patient and midwife (Perdok et al., 2018).

However, there are other forms of continuity of care, these include "information continuity" whereby healthcare providers exchange information about the patients for appropriate care; and "management continuity" whereby healthcare providers coherently provide care by connecting to one another (Haggerty eta al. Cited in Perdok, et al. 2018). Research findings had it that personal continuity of care is associated with reduced preterm birth, or miscarriage (Sandall et al., 2016), and fewer interventions in pregnancy and delivery (Sandall et al., 2015). Geller et al. (2018) postulated that the mother's health and wellbeing is a crucial factor that is closely associated with newborn child's good health and survival. Thus, MCC can be a means of improving children health.

In a study by Rayment-Jones et al. (2015), women with complex social factors in caseload midwifery model had fewer caesareans, fewer antenatal admissions and shorter length of postnatal hospitalization. They are more likely to be referred to specialist services; and their babies had low neonatal admissions. Women in MCC have greater satisfaction with advices, explanation, information, delivery venue, labour and birth, behaviour of the midwife, choice for pain relief, and feel less anxious (Mclachlan et al., 2015). Based on these kind of research evidences, the WHO has recommended scaling up the midwifery care that facilitate continuity (Mortensen et al., 2018).

The midwifery continuity of care is gaining more attention (Burau \& Overgaard, 2015), and the WHO recommends the use of midwifery continuity of care models to provide antenatal, intrapartum and postnatal care in a setting where effective midwifery programme exists (WHO, 2016b). However, implementation of continuity of care model has been challenging in many countries (Homer et al., 2017). According to Homer et al. (2017) and Dawson et al. (2018), for midwives, and in many countries implementing continuity of care is a challenge. Applying midwifery continuity of care therefore, requires midwives willingness to sustain the new model throughout the antenatal, intrapartum and postnatal periods (Taylor et al., 2019).

Most of the researches on midwife led continuity of care were conducted in developed countries (Graham et al., 2016; Sandall et al., 2016); and utilising this model of care is challenging in developing countries. Therefore, for the prospective thinking of implementing MCC there is need to assess the midwives' potentiality to

\section{Yahaya Jafaru}

Department of Nursing Science, College of Health Sciences, Federal University Birnin-Kebbi, Kebbi State, Nigeria. Email: jafaruyahaya2015@yahoo.com 
adhering to MCC in developing countries. This will give an idea on whether the midwives are having positive thinking and potentiality to adhere to MCC or not. Thus, this research was aimed at assessing the potentiality of midwives adherence to midwifery continuity of care as a new model of care.

\section{RESEARCH METHODS}

The research was descriptive that adopted cross-sectional design to assess the potentiality of midwives adherence to midwifery continuity of care as a new model of care in Sir Yahaya Memorial Hospital Birnin-Kebbi, Kebbi State, Nigeria. The population of the study was the midwives serving in antenatal clinic (ANC), maternity and labour units of the hospital. The instrument for data collection was 27 items, researcher made, self-administered questionnaire. The questionnaire is made up of 2 sections, section $A$ and section $B$. Section $A$ consists of 2 questions that assess the demographic variables of the respondents; while section B consists of 25 questions that assess the respondents potentiality to $\mathrm{MCC}$ adherence using 5 point Likert scale of $1=$ strongly disagree, $2=$ disagree, $3=$ =neutral, 4=agree and 5=strongly agree. It assess the agreement and disagreement of the positive impact of MCC on pregnancy in ante-natal, intra-natal and post-natal period as potentiality of midwives to adhere to MCC. Three experienced nurse-midwives vetted the questionnaire and they ascertained its face and content validity.

The reliability of the instrument was 0.966 using Cronbach's alpha. Census sampling was used in taking the entire midwives of the units as the subjects of the study. The ethical approval to conduct the research was obtained from Kebbi state health research ethical Committee, with assigned number 105:4/2020. Permission to conduct the research was also taken from the hospital management, and data were collected from 24 th February 2020 to $20^{\text {th }}$ March 2020, with the response rate of $100 \%$. SPSS version 16 was used in data analysis; and the results were presented using frequencies and percentages, with Chi-square as a statistical tool for inferential analysis.

\section{RESEARCH RESULTS}

Table 1 shows the demographic variables of the respondents; in which $44.8 \%$ of the respondents were having $0-5$ years of working experience, and $16.4 \%$ were having more than 15 years of experience. Majority (61.2\%) of the respondents were nurse-midwives, while $38.8 \%$ were midwives.

Table 1 Percentage Distribution of Respondents' Demographic Variables N=68

\begin{tabular}{lcc}
\hline Variables & Frequency & Percetage \\
\hline Years of Experience & 30 & \\
$0-5$ & 17 & 44.8 \\
$6-10$ & 9 & 25.4 \\
$11-15$ & 11 & 13.4 \\
$>15$ & & 16.4 \\
& & \\
Specialization & 26 & 38.8 \\
Midwife & 41 & 61.2 \\
Nurse-midwife & & \\
\hline
\end{tabular}

Table 2 indicates that majority of the respondents either agree or strongly agree with most of the items of the instrument. However, some of the items have majority of the respondents disagree or strongly disagree; and most of these items are those postulating negative effect if the midwife is not familiar with pregnant woman. This is found in items 13-16. These items are also shown to have the lowest means.

\section{Yahaya Jafaru}

Department of Nursing Science, College of Health Sciences, Federal University Birnin-Kebbi, Kebbi State, Nigeria. Email: jafaruyahaya2015@yahoo.com 


\section{Table 2: Respondents' Level of Potentiality to MCC Adherence by Questionnaire Items}

\begin{tabular}{|c|c|c|c|c|c|c|c|}
\hline $\mathbf{S} / \mathbf{N}$ & Questionnaire Items & SD & $\bar{D}$ & $\mathbf{N}$ & $\mathrm{A}$ & SA & M/SD \\
\hline & & F/P & F/P & F/P & F/P & F/P & \\
\hline 1. & $\begin{array}{l}\text { Pregnant woman should have easy access to a midwife as first point of professional contact when } \\
\text { pregnant }\end{array}$ & $12 / 17.9$ & $0 / 0.0$ & $3 / 4.5$ & $14 / 20.9$ & $38 / 56.7$ & $3.99 / 1.50$ \\
\hline 2. & $\begin{array}{l}\text { Pregnant women should receive majority of their midwifery care by single and same experienced } \\
\text { midwife, including prenatal, intra-natal and postnatal care }\end{array}$ & $12 / 17.9$ & $15 / 22.4$ & $8 / 11.9$ & $16 / 23.9$ & $16 / 23.9$ & $3.13 / 1.47$ \\
\hline 3. & $\begin{array}{l}\text { Pregnant woman should have 24-hour access to advices and supports from single and same } \\
\text { experienced midwife, including prenatal, intra-natal and postnatal care }\end{array}$ & $10 / 14.9$ & $13 / 19.4$ & $7 / 10.4$ & $19 / 28.4$ & $18 / 26.9$ & $3.33 / 1.44$ \\
\hline 4. & $\begin{array}{l}\text { Providing care by a single and same experienced midwife is more affordable and sustainable model } \\
\text { of maternity care }\end{array}$ & $12 / 17.9$ & $13 / 19.4$ & $11 / 16.4$ & $21 / 31.3$ & $10 / 14.9$ & $3.06 / 1.36$ \\
\hline 5. & $\begin{array}{l}\text { To effectively care for a woman, midwives should be able to directly refer to other } \\
\text { professionals/agencies (when need arise) and receive referrals back }\end{array}$ & $6 / 9.0$ & $8 / 11.9$ & $2 / 3.0$ & $15 / 22.4$ & $36 / 53.7$ & $4.00 / 1.37$ \\
\hline 6. & $\begin{array}{l}\text { Providing care by a single and same experienced midwife can best ensure the right care by the right } \\
\text { health professionals in the right setting and at right time }\end{array}$ & $12 / 17.9$ & $13 / 19.4$ & $9 / 13.4$ & $18 / 26.9$ & $15 / 22.4$ & $3.16 / 1.44$ \\
\hline 7. & $\begin{array}{l}\text { Providing care by a single and same experienced midwife can provide best means for achieving } \\
\text { woman's needs. }\end{array}$ & $10 / 14.9$ & $12 / 17.9$ & $7 / 10.4$ & $18 / 26.9$ & $19 / 28.4$ & $3.36 / 1.45$ \\
\hline
\end{tabular}

\section{Yahaya lafaru}

Department of Nursing Science, College of Health Sciences, Federal University Birnin-Kebbi, Kebbi State, Nigeria.

Email: jafaruyahaya2015@yahoo.com 
8. Providing care by a single and same experienced midwife can provide safer services with quality maternal and neonatal outcomes based on best practice

9. Providing care by a single and same experienced midwife provides woman with informed choice and greater control of her birthing experience

10. Providing care by a single and same experienced midwife can provide best means for evidencebased midwifery care

11. Assigning each experienced midwife a specific number of women to care for through pregnancy, labour and post natal period makes midwifery more effective

12. Assigning each experienced midwife a specific number of women to care for through pregnanc labour and post natal period develops a trusting relationship

13. Seen different midwives by pregnant woman at different visits can negatively affect pregnancy outcome

14. Pregnant woman should have one-to-one care by a midwife she is familiar to when in established labour

15. Seen a midwife that is not familiar to a woman during labour can negatively affects labour outcome

$16 / 23.9$

$19 / 28.4$

$1 / 16.4$

$9 / 13.4$

$17 / 25.4$

$17 / 25.4$

$3.21 / 1.48$

16. Seen a midwife that is not familiar to a woman during postpartum period can negatively affects

$18 / 26.9$

$8 / 11.9$

$18 / 26.9$

15/22.4

$3.18 / 1.41$

$9 / 13.4$

$7 / 10.4$

7/10.4

$27 / 40.3$

$17 / 25.4$

$3.54 / 1.34$

$10 / 14.9$

$10 / 14.9$

$9 / 13.4$

$16 / 23.9$

$22 / 32.8$

$3.45 / 1.46$

$11 / 16.4 \quad 7 / 10.4$

$8 / 11.9$

$23 / 34.3$

$18 / 26.9$

$3.45 / 1.42$ postpartum outcome

$22 / 32.8$

$18 / 26.9$

$6 / 9.0$

$12 / 17.9$

9/13.4

$2.52 / 1.45$

$15 / 22.4$

$22 / 32.8$

$6 / 9.0$

$13 / 19.4$

$11 / 16.4$

$2.75 / 1.43$

\section{Yahaya Jafaru}

Department of Nursing Science, College of Health Sciences, Federal University Birnin-Kebbi, Kebbi State, Nigeria.

Email: jafaruyahaya2015@yahoo.com 
17. Providing care by a single and same experienced midwife can best promote woman's satisfaction

$14 / 20.9$

$7 / 10.4$

$6 / 9.0$

$24 / 35.8$

$16 / 23.9$

$3.31 / 1.48$ during pregnancy and childbirth

18. Providing care by a single and same experienced midwife can best enable woman's participation in decision making relating to her care

19. Providing care by a single and same experienced midwife can enhance a maternity team approach

$9 / 13.4$

$11 / 16.4$

$25 / 37.3$

$12 / 17.9$

$3.30 / 1.33$

20. Providing care by a single and same experienced midwife is important in monitoring human resource

$11 / 16.4$

$17 / 25.4$

$17 / 25.4$

$12 / 17.9$

$10 / 14.9$

$2.90 / 1.30$

$8 / 11.9$

$13 / 19$

$16 / 23.9$

$15 / 22.4$

$15 / 22.4$

$3.24 / 1.33$ use in midwifery

21. Providing care by a single and same experienced midwife is valuable and safe for women with varying levels of risk in their pregnancy

22. Providing care by a single and same experienced midwife is beneficial to woman with complex pregnancy

23. Providing care by a single and same experienced midwife can contribute to safety, reduction in stillbirth, neonatal death and maternal death rates.

24. Providing care by a single and same experienced midwife can contribute to woman centered care and personalised care plan

25. Providing care by a single and same experience midwife can contributes to ensuring an increased focus on multi-disciplinary working
$15 / 22.4$

$15 / 22.4$

$13 / 19.4$

$13 / 19.4$

$11 / 16.4$

$2.85 / 1.41$

$14 / 20.9$

$21 / 31.3$

$4 / 6.0$

$14 / 20.9$

$14 / 20.9$

$2.90 / 1.49$

$8 / 11.9$

$20 / 29$

$13 / 19.4$

$14 / 20.9$

$12 / 17.9$

$3.03 / 1.31$

10/14.9

$14 / 20$

$10 / 14.9$

$20 / 29.9$

$13 / 19.4$

$3.18 / 1.37$

$7 / 10.4$

$18 / 26.9$

$11 / 16.4$

$11 / 16.4$

$20 / 29.9$

$3.28 / 1.41$

\section{Key: SD = Strongly disagree, $\mathrm{D}$ = Disagree, $\mathrm{N}$ = Neutral, $\mathrm{A}$ = Agree, $\mathrm{SA}$ = Strongly agree, $\mathrm{M}$ = Mean, SD = Standard deviation}

\section{Yahaya lafaru}

Department of Nursing Science, College of Health Sciences, Federal University Birnin-Kebbi, Kebbi State, Nigeria.

Email: jafaruyahaya2015@yahoo.com 
Table 3 reveals the level of respondents' potentiality to MCC adherence. It shows that $46.3 \%$ of the respondents were having good potentiality, $44.8 \%$ were having poor potentiality, and only $9.0 \%$ were having very good potentiality. It also reveals $56.7 \%$ of the respondents with $0-5$ years of experience were having poor potentiality to MCC adherence, in contrast with $27.3 \%$ in respondents with $>15$ years of experience. However, in good potentiality level, $26.7 \%$ of the respondents with $0-5$ years of experience were having good potentiality, in contrast with $72.7 \%$ in respondents with $>15$ years of experience. Also, table 3 indicates that there is no significant association between respondents' years of experience and their level of potentiality to MCC adherence, $P>0.05$.

Table 3. Respondents' Level of Potentiality to MCC Adherence by Respondents' Years of Experience

\begin{tabular}{|c|c|c|c|c|c|c|c|}
\hline \multirow{2}{*}{$\begin{array}{l}\text { Level of } \\
\text { Potentiality }\end{array}$} & \multicolumn{5}{|c|}{ Years of Experience } & \multirow[t]{2}{*}{$X^{2}$} & \multirow[t]{2}{*}{$\mathbf{P}$} \\
\hline & $\begin{array}{c}0-5 \\
F(P)\end{array}$ & $\begin{array}{l}6-10 \\
F(P)\end{array}$ & $\begin{array}{c}11-15 \\
F(P)\end{array}$ & $\begin{array}{l}>15 \\
F(P)\end{array}$ & $\begin{array}{l}\text { Total } \\
F(P)\end{array}$ & & \\
\hline Poor Potentiality & $17(56.7)$ & $7(41.2)$ & $3(33.3)$ & $3(27.3)$ & $30(44.8)$ & 9.55 & 0.09 \\
\hline Good Potentiality & $8(26.7)$ & $9(52.9)$ & $6(66.7)$ & $8(72.7)$ & $31(46.3)$ & & \\
\hline $\begin{array}{l}\text { Very Good } \\
\text { Potentiality }\end{array}$ & $5(16.7)$ & $1(5.9)$ & $0(0.0)$ & $0(0.0)$ & $6(9.0)$ & & \\
\hline
\end{tabular}

Table 4 indicates that $50 \%$ and $41.5 \%$ of the respondents that were midwives and those that were nursemidwives in specialty respectively were having poor potentiality to MCC adherence. However, $34.6 \%$ and $53.7 \%$ of the respondents that were midwives and those that were nurse-midwives in specialty respectively were having good potentiality to MCC adherence. But $15.4 \%$ midwives in specialty were having very good potentiality in contrast with only $4.9 \%$ nurse-midwives. There is no significant association between respondents' specialty and their level of potentiality to MCC adherence, $P>0.05$ (Table 3 ).

Table 4. Respondents' Level of Potentiality to MCC Adherence by Respondents' Specialization

\begin{tabular}{|c|c|c|c|c|c|}
\hline \multirow[t]{2}{*}{ Level of Potentiality } & \multicolumn{3}{|c|}{ Specialization } & \multirow[t]{2}{*}{$\mathrm{X}^{2}$} & \multirow[t]{2}{*}{$\mathbf{P}$} \\
\hline & $\begin{array}{l}\text { Midwife } \\
F(P)\end{array}$ & $\begin{array}{c}\text { Nurse-midwife } \\
F(P)\end{array}$ & $\begin{array}{l}\text { Total } \\
F(P)\end{array}$ & & \\
\hline Poor Potentiality & $13(50)$ & $7(41.5)$ & $30(44.8)$ & 3.40 & 0.18 \\
\hline Good Potentiality & $9(34.6)$ & $22(53.7)$ & $31(46.3)$ & & \\
\hline Very good Potentiality & $4(15.4)$ & $2(4.9)$ & $6(9.0)$ & & \\
\hline
\end{tabular}

\section{DISCUSSION}

Though, the respondents with good potentiality to MCC adherence were having highest percentage, but the level of poor potentiality is also high; the difference between good potentiality and poor potentiality is very limited. This may be due to the fact that MCC is not existing in the hospital of the study; and the staff were used to traditional practice of midwifery. It can be evident in which very small percentage had very good potentiality to MCC adherence. This finding is in agreement with finding of a research by Taylor et al. (2018) to

\section{Yahaya Jafaru}

Department of Nursing Science, College of Health Sciences, Federal University Birnin-Kebbi, Kebbi State, Nigeria. Email: jafaruyahaya2015@yahoo.com 
explore midwives' perspectives of different ways of working, it was revealed that the number of midwives needed to implement continuity of care was inadequate due to gap in midwives' acceptance of the model. This leads to the call for modifications on MCC, because it is asserted that midwives can change to MCC if it comes with flexible working patterns (Jepsen et al. 2016; Newton et al., 2016). This finding is also in line with a cross sectional survey by Taylor et al. (2019) to study the Midwives' perspectives of continuity based working in the UK, where it was found that some midwives suggested that current approaches to delivering care were working well, with good ante and postnatal continuity, and questioned the need for change (Taylor et al., 2019).

Since the good potentiality was having highest percentage and when combined with very good potentiality, it can be said that majority of the respondents were having positive potentiality toward MCC adherence. This finding is in agreement with a research by Sidebotham et al. (2015) to study perception of midwives on their role within the context of maternity service reform. It was found that midwives accepted the concept of continuity of midwifery care as important and required maternity care system that is woman centered. It is however, contrary to a research by Taylor et al. (2018) to explore midwives' perspectives of different ways of working, where it was found that many midwives report barriers to being able to change the way they work to make continuity happen.

From the result of this study, it is revealed that majority of the respondents showed an agreement with most of the items of the instrument, except in items 13-16 in which majority of the respondents showed there disagreement. This is probably because the items with high disagreement are those postulating negative effect of unfamiliarity between pregnant woman and midwife; and the existing system of midwifery practice in the country is highly associated with unfamiliarity between pregnant woman and midwife. Thus, to increase the potentiality of midwives' adherence to MCC, there is need for passing awareness about MCC among midwives. This is because the MCC is solely dependent on relationship between pregnant woman and midwife; and familiarity between them influence the relationship, thereby impacting the pregnancy and its outcomes positively.

The result of this study revealed that, the level of poor potentiality is decreasing with the increase in years of experience. Respondents with the 0-5 years of experience had majority with poor potentiality, while the respondents with $>15$ years of experience were having few poor potentiality. In contrast, the good potentiality is increasing with the increase in years of experience. However, in very good potentiality, the presentation becomes odd, in which no respondents had very good potentiality among respondents with $11-15$ and $>15$ years of experience respectively. It might be possible, years of experience influence the potentiality to MCC adherence, and thus working experience might have an impact on respondents' potentiality. This is in accordance with the assertion by some researchers that continuous exposure of midwives and students to MCC could cause an increased in awareness and interest (Carter et al., 2015; Dawson et al., 2018), even though in this case the exposure was not on MCC.

The only midwives in specialty respondents were having higher poor potentiality to MCC adherence than their counterpart that were nursemidwives. Also the nurse-midwives were having higher good potentiality compared to those that were midwives only. However, respondents that were midwives only in specialty were having higher very good potentiality. Thus, the trend of the potentiality level is in favour of nurse-midwives except in very good potentiality where nursemidwives were having lower potentiality. Nevertheless, when good potentiality and very good potentiality are added together, the nursemidwives were having higher percentage than the midwives only specialty respondents.

Owing to differences in culture and traditions between developed and developing countries, certain modifications might be necessary when implementing MCC in developing countries. The modifications and MCC flexibility of MCC to suit the local environment would help the midwives in developing countries to adhere to MCC more quickly. Therefore, there is need for passing awareness and imparting more knowledge about

\section{Yahaya Jafaru}

Department of Nursing Science, College of Health Sciences, Federal University Birnin-Kebbi, Kebbi State, Nigeria. Email: jafaruyahaya2015@yahoo.com 
MCC to midwives in order to increase their understanding on this model of midwifery care. Thus, conferences, seminars and professional development programmes could be used as a ground for updating knowledge, sensitizing colleagues and educating self about MCC; and thereby increasing the level of acceptance of this model of care.

\section{CONCLUSION}

It is mostly accepted that MCC supports client's centered care and bring about trust, respect, dignity and empowerment to both women and midwives. The respondents of this study had a moderately positive potentiality to MCC adherence. This could be attributed to non-existence of any of its model in the hospital of the study or virtually absent in Nigerian midwifery care system. There is need for policy makers and professional organisations in developing countries to consider MCC implementation; sensitise the midwives by passing awareness and updating knowledge about this model of midwifery care. The acceptance and potentiality to MCC adherence can be improved if it is introduced into the system with some modifications and flexibilities; and when the midwives realise its positive impact on maternal and new-born health.

\section{REFERENCES}

Blencowe, H., Cousens, S., Bianchi, J.F., Say, L., Chou, D., Mathers, C., Hogan, D., Shiekh, S., Qureshi, Z.U., $\quad$ You, D. \& Lawn, J.E. (2016). National, regional, and worldwide estimates of stillbirth rates in 2015 , with trends from 2000: a systematic analysis. Lancet; 4(2):e98-108. doi:10.1016/S2214$109 \times(15) 00275-2$.

Boyle, S., Thomas, H. \& Brooks, F. (2016). Women's views on partnership working with midwives during pregnancy and childbirth. Midwifery 32:21-9. doi: 10.1016/j.midw.2015.09.001.
Burau, V. \& Overgaard, C. (2015). Caseload midwifery as organisational change: the interplay between professional and organisational projects in Denmark. BMC Pregnancy and Childbirth. 15:121. Doi: https://doi.org/10.1186/s12884-015-0546-8

Carter, A.G., Wilkes, E., Gamble, J., Sidebotham, M. \& Creedy, D.K. (2015). Midwifery students' experiences of an innovative clinical placement model embedded within midwifery continuity of care in Australia. Midwifery 31, 765-771. doi: 10.1016/j.midw.2015.04.006.

Dawson, K., Forster, D.A., McLachlan, H.L. \& Newton, M.S. (2018). Operationalising caseload midwifery in the Australian public maternity system: findings from a national cross-sectional survey of maternity managers. Women Birth 31, 194-201. doi: 10.1016/j.wombi.2017.08.132.

Geller, S.E., Koch, A.R., Garland, C.E., MacDonald, E.J., Storey, F. \& Lawton, B. (2018). A global view of severe maternal morbidity: moving beyond maternal mortality. Reprod. Health;15:98. doi:10.1186/s12978018- $\quad 0527-2$

Graham, W., Woodd, S., Byass, P., Filippi, V., Gon, G., Virgo, S., Chou, D., Hounton, S. Lozano, R. Pattinson, R. \& Singh, S. (2016). Diversity and divergence: the dynamic burden of poor maternal health. Lancet; 388:2164-75. DOI: 10.1016/S01406736(16)31533-1

Homer, C.S., Leap, N., Edwards, N., \& Sandall, J. (2017). Midwifery continuity of care in an area of high socio- economic disadvantage in London: A retrospective analysis of Albany Midwifery Practice outcomes using routine data (1997-2009). Midwifery 48, 1-10. doi: 10.1016/j.midw.2017.02.009.

\section{Yahaya Jafaru}

Department of Nursing Science, College of Health Sciences, Federal University Birnin-Kebbi, Kebbi State, Nigeria. Email: jafaruyahaya2015@yahoo.com 
Jepsen, I., Mark, E., Nøhr, E.A., Foureur, M. \& Sørensen, E.E. (2016). A qualitative study of how caseload midwifery is constituted and experienced by Danish midwives. Midwifery 36 , 61-69. doi: $\quad$ 10.1016/j.midw.2016.03.002.

Killingley, Jo (2016). Sustainable birth:caseloading. MIDIRS Midwifery Digest, 26 (4). pp. 452-453.

McLachlan, H.L., Forster, D.A., Davey, M.A., Farrell, T., Flood, M., Shafiei, T. \& Waldenström, U. (2015). 'The effect of primary midwife-led care on women's experience of child birth - the results of the COSMOS trial', BJOG in press. https://doi.org/10.1111/1471- 0528.13713

Miller S, Abalos E, Chamillard M , Ciapponi, A., Colaci, D., Comandé, D., Diaz, V., Geller, S., Hanson, C., Langer, A., Manuelli, V., Millar, K., Morhason-Bello, I., Castro, C.P., Pileggi, V.N., Robinson, N., Skaer, M., Souza, J.P., Vogel, J.P. \& Althabe, F. (2016). Beyond too little, too late and too much, too soon: a pathway towards evidence-based, respectful maternity care worldwide. Lancet 2016;388:2176-92.doi:10.1016/S0140-6736 (16)31472-6

Mortensen, B., Lukasse, M., Diep, L.M. Lieng, M., Abu-Awad, A. Suleiman, M., \& Fosse, E. (2018). Can a midwife- led continuity model improve maternal services in a low-resource setting? A non-randomised cluster intervention study in Palestine. BMJ Open; 8:e019568.doi:10.1136/bmjopen-2017019568

National Maternity Review (2016). Better Births. Improving outcomes of maternity services in England. A Five Year Forward View for maternity care.

Newton, M.S., Mclachlan, H.L., Forster, D.A. \& Willis, K.F. (2016). Understanding the 'work' of caseload midwives: a mixed-methods exploration of two caseload midwifery models in
Victoria, Australia. Women Birth 29, 223-233. doi:10.1016/j.wombi.2015.10.011.

Okeke, E., Glick, P., Abubakar, I.S., Chari, A.V., Pitchforth, E., Exley, J., Bashir, U., Setodji, C., Gu, K. \& Onwujekwe, O, (2017). The Better Obstetrics in Rural Nigeria study: an impact evaluation of the Nigerian Midwives Service Scheme, 3ie Impact Evaluation Report 56, New Delhi: International Initiative for Impact Evaluation (3ie).

Oyetunde, M.O. (2014). Quality issues in midwifery: A critical analysis of midwifery in Nigeria within the context of the International Confederation of Midwives (ICM) global standards. International Journal of Nursing and Midwifery. Vol. 6(3), pp. 40-48, July 2014 DOI: 10.5897/IJNM2013-0119

Perdok, H., Verhoeven, C., van Dillen, J., Schuitmaker, T.J., Hoogendoorn, K., Colli, J., Schellevis, F.G., \& de Jonge A. (2018). Continuity of care is an important and distinct aspect of childbirth experience: findings of a survey evaluating experienced continuity of care, experienced quality of care and women's perception of labor. BMC Pregnancy Childbirth 18, 13. https://doi.org/10.1186/s12884-017-1615-y

Rayment-Jones, H., Murrells, T. \& Sandall, J. (2015). 'An investigation of the relationship between the caseload model of midwifery for socially disadvantaged women and childbirth outcomes using routine data-a retrospective, Observational study'. Midwifery, 31(4): 409417. DOI: 10.1016/j.midw.2015.01.003

Sandall, J., Coxon, K., Mackintosh, N., RaymentJones, H., Locock, L. \& Page, L. (2016). (writing on behalf of the Sheila

Kitzinger symposium) Relationships: the pathway to safe, high-quality maternity care. Report from the Sheila Kitzinger symposium at Green Templeton College October 2015. Green Templeton College, Oxford.

\section{Yahaya Jafaru}

Department of Nursing Science, College of Health Sciences, Federal University Birnin-Kebbi, Kebbi State, Nigeria. Email: jafaruyahaya2015@yahoo.com 
Sandall, J., Soltani, H., Gates, S., Shennan, A. \& Devane, D. (2015). Midwife-led continuity models versus other models of care for childbearing women. Cochrane Database Syst Rev. 9:CD004667. https://doi.org/10.1002/14651858.CD004667.

Sidebotham, M., Fenwick, J., Rath, S. \& Gamble, J. (2015). Midwives' perceptions of their role within the context of maternity service reform: An Appreciative Inquiry. Women and Birth. Volume 28, Issue 2, June 2015, Pages 112-120. doi: 10.1016/j.wombi.2014.12.006.

Taylor, B., Cross-Sudworth, F. \& MacArthur, C. (2018). Better Births and Continuity: Midwife Survey Results. Accessed $20^{\text {th }}$ January 2020, Retrieved from: https://www.google.com/url?sa=t\&rct=i\&q=\&esr $\mathrm{c}=\mathrm{s} \&$ source $=$ web\&cd $=1 \& \mathrm{cad}=$ rja\&uact $=8 \&$ ved $=$ 2ahUKE wi1soz_i6LnAhXFxYUKHazADKUQFjAAegQIB

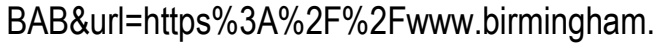
ac.uk\%2F Documents\%2Fcollegemds\%2Fapplied-health\%2Fbetter-birth-andcontinuity.pdf\&usg=AOVVaw3FGSMjOIzWmrVI 7eHVUyld
Taylor, B., Cross-Sudworth, F., Goodwin, L., Kenyon, S., \& MacArthur C. (2019). Midwives' perspectives of continuity based working in the UK: A cross-sectional survey. Midwifery 75 127-137. doi: 10.1016/j.midw.2019.05.005.

World Health Organisation (2014). Maternal mortality. Fact sheet No. 348; Geneva: (http://www.who.int/mediacentre/factsheets/fs3 48/en/ index.html, accessed 22 ${ }^{\text {nd }}$ June 2019).

World Health Organisation (2016a). WHO recommendations on antenatal care for a positive pregnancy experience. https://apps.who.int/iris/bitstream/handle/10665/ 250796/9789241549912eng.pdf;jsessionid=3D 067F2817A274DEDF22520163E97D4E?seque nce $=1$. Accesses $6^{\text {th }}$, May 2019

World Health Organization (2016b). WHO recommendation on midwife-led continuity of careduring pregnancy. Accessed $15^{\text {th }}$ June 2019. Retrieved from: https://extranet.who.int/rhl/topics/improvinghealth-system-performance/implementation strategies/who-recommendation-midwifeledcontinuity care-during- pregnancy

\section{Yahaya Jafaru}

Department of Nursing Science, College of Health Sciences, Federal University Birnin-Kebbi, Kebbi State, Nigeria. Email: jafaruyahaya2015@yahoo.com 